\title{
SINEMA TERBUKA SEBAGAI RUANG KETIGA DI JAKARTA
}

\author{
Tramilia Salsabila Utami ${ }^{1}$, Nina Carina ${ }^{2)}$ \\ 1)Program Studi S1 Arsitektur, Fakultas Teknik, Universitas Tarumanagara, \\ tramiliasalsabilautami@yahoo.com \\ 2)Program Studi S1 Arsitektur, Fakultas Teknik, Universitas Tarumanagara, ninac@ft.untar.ac.id
}

Masuk: 14-07-2020, revisi: 01-08-2020, diterima untuk diterbitkan: 05-09-2020

\begin{abstract}
Abstrak
Bioskop di Jakarta umunya berada di dalam pusat perbelanjaan besar di Jakarta. Bioskop saat ini menjadi tujuan namun belum menjadi sebuah third place. Minimnya third place di Kota Jakarta yang dapat memberikan wadah untuk berkumpul, titik temu, dan menyediakan sebuah hiburan membuat warga Jakarta menjadikan bangunan komersil sebuah third place. Bagaimana desain dan program sebuah bioskop yang dapat memenuhi syarat dan ketentuan sebuah third place dengan melihat fenomena bioskop di Jakarta saat ini. Open cinema atau sinema terbuka mengambil konsep layar tancap atau misbar yang dari dulu sudah ada di Indonesia. Layar tancap yang tujuan utamanya adalah untuk memberikan hiburan di daerah yang sulit dijangkau ternyata dapat diterapkan di kota besar. Dalam pembahasan sebuah bioskop seharusnya dapat menjadi ruang ketiga sehingga dapat membuat penggunanya merasa nyaman, dengan memberikan aktivitas utama menonton film. Open Cinema diharapkan dapat menjadi third place yang dapat menyediakan hiburan menonton di Jakarta tanpa harus datang ke bioskop di pusat perbelanjaan kota seperti bioskop saat ini. Open Cinema dapat menjadi sebuah third place di kota Jakarta, yang memberikan hiburan menonton dengan suasana yang berbeda, berusaha memberikan ruang hiburan dan interaksi bagi masyarakat.
\end{abstract}

\section{Kata Kunci: Entertainment; Open Cinema; Third place}

\begin{abstract}
Cinema in Jakarta generally located in a shopping mall in Jakarta. Cinema nowadays becomes a destination for people but not yet become a third place. The lack of third place in Jakarta that can provide a place for gathering, as a meeting point, and entertainment makes Jakarta residents used commercial building as a third place. Looking at the design and program a cinema that can meet the conditions and characteristics of a third place by looking at the phenomenon cinema in Jakarta. Open cinema takes layar tancap concept or "misbar" that have been established in Indonesia. The purpose of layar tancap is to give an entertainment in areas that are difficult to reach, apparently can be applied in the city. Under the discussion, a cinema should be able to become the third place so that makes the visitor feel comfortable, with the main activity is watching a movie. Open cinema is expected to become a third place that can provide entertainment watching a movie in Jakarta without having to come to a cinema in a shopping center. Cinema that can become a third place in Jakarta. Giving a cinema with a different atmosphere, trying to give space for people to interact while providing entertainment.
\end{abstract}

Keywords: Entertainment; Open Cinema; Third place

\section{PENDAHULUAN}

\section{Latar Belakang}

Bioskop umumnya berada di dalam pusat perbelanjaan yang besar di Jakarta. Bioskop saat ini menjadi tujuan namun belum menjadi sebuah third place. Minat masyarakat Jakarta dalam menonton masyarakat masih tetap tinggi terlepas dari maraknya menonton film melalui 
streaming di internet. Berdasarkan data dari filmindonesia.oid.id pada tahun 2019, pengunjung tahun 2017 sebanyak 42,7 juta penonton, meningkat menjadi 52 juta pada tahun 2018 dan 60 juta penonton pada tahun 2019. Dari data tersebut menunjukkan bahwa minat masyarakat Jakarta untuk menonton film di bioskop makin tinggi setiap tahunnya. Menonton bioskop juga menjadi minat bagi kalangan millenial. Menurut artikel tirto.id, alasan dari kalangan millenial menonton bioskop adalah salah satu alternatif aktivitas untuk istirahat dari gadget dan media sosial. Memberikan motivasi untuk berkomunikasi dengan teman sebaya dan memiliki kemampuan yang memadai untuk berdiskusi usai menonton film. Dari bahasan diatas bioskop dapat menjadi wadah untuk berinteraksi bagi warga kota.

Masyarakat kota Jakarta umumnya menjadikan third place sebagai tempat untuk lari dari rutinitas yang biasa dilakukan. Menjadi tempat untuk rehat sejenak dari second place (tempat kerja atau sekolah) dan menjadi wadah saat bosan berada di first place (rumah). Third place yang dapat menyediakan entertainment menjadi salah satu program yang digunakan. Kurangnya ruang kota di Jakarta untuk bertemu, berinteraksi serta menyediakan hiburan membuat masyarakat kota datang ke bangunan komersil. Bangunan komersil saat ini digunakan sebagai titik temu, tempat berkumpul, dan menjadi salah satu hiburan yang ada di kota.

Batasan permasalahan membahas bagaimana keadaan bioskop di kota Jakarta saat ini. Melihat bagaimana sebuah third place di Jakarta dan bioskop pada saat ini. Mengkaji bioskop yang pernah ada dan membandingkan dengan bioskop yang bekerja masa sekarang. Bioskop/ cinema di Jakarta saat ini tidak dapat dikatakan sebuah third place, hanya beberapa bioskop komunitas yang berdiri secara independen. Aspek apa saja yang perlu diperhatikan dalam sebuah bioskop sehingga dapat menjadi sebuah third place bagi masyarakat kota Jakarta. Bioskop di Jakarta selama ini lebih privat dan komersil, hanya beberapa bioskop yang dapat menjadi wadah untuk memulai conversation, maupun berinteraksi. Sebuah Open cinema yang dimaksud yaitu bioskop terbuka, dari fungsi maupun desainnya tidak seperti bioskop pada umumnya di Jakarta. Open cinema membuat bioskop yang dapat menjadi sebuah third place, memberikan suasana dan kesan menonton yang berbeda dan lebih bebas dari yang bioskop yang ada selama ini.

\section{Rumusan Masalah}

a. Bioskop dengan program yang bagaimana sehingga dapat dikatakan sebuah third place

b. Aktivitas apa yang akan dibuat sehingga membuat pengguna bioskop berinteraksi lebih

c. Membahas desain sebuah bioskop yang dapat memenuhi ketentuan sebuah third place

d. Membahas bagaimana sebuah bioskop/cinema dapat menjadi sebuah third place menjadi sesuatu yang perlu dibahas.

\section{Tujuan Open Cinema}

a. Membuat bioskop menjadi sebuah third place di Jakarta.

b. Memberikan suasana menonton yang berbeda dan lebih bebas dari bioskop yang sudah ada di Jakarta saat ini.

c. Menjadikan bioskop menjadi wadah yang dapat memulai interaksi bagi penggunanya. 


\section{KAJIAN LITERATUR}

\section{Third place}

Ruang ketiga atau third place yang dapat memberikan keseimbangan diantara first place (rumah) dan second place (kantor atau sekolah) atau sebuah tempat untuk melakukan kegiatan produktif. Third place menjadi ruang dimana masyarakat kota dapat bersosialisasi, menawarkan sebuah komunitas ke masyarakat sekitar. Dapat memberikan pengalaman yang dibangun berdasarkan hubungan sosial yang terjalin, semuanya memiliki bentuk dan tempat yang berbeda, yang dapat menyesuaikan dengan karakteristik lokasi.

Sebuah ruang yang dapat menjadi third realm dari perasaan yang dirasakan saat berada di rumah atau kantor. Kehidupan publik informal terlihat seperti tidak terlalu penting tetapi dalam kenyataannya sangat diperlukan. Kehidupan yang dapat menyeimbangkan inti dari kehidupan yang dijalankan oleh masyarakat kota. Dalam sebuah kehidupan publik informal, masyarakat memiliki ekspektasi kepada pekerjaan dan kehidupan pribadi yang memiliki ekspektasi jauh diatas yang diharapkan. Pribadi dan hubungan pekerjaan dicampur menjadi sebuah tekanan dan sebenarnya yang dibutuhkan hanya sebuah kehidupan terlepas dari dua aspek diatas.

Menurut Ray Oldenburg (1997) dalam buku The Good Great Place, Third place sebagai core setting bagi kehidupan publik informal. Third place dapat menjadi destinasi umum untuk berbagai macam ruang publik. Menurut Ray Oldenburg, Third place memiliki 8 syarat yaitu:

a. Third place sebagai neutral ground

Tidak ada keterikatan masyarakat yang menggunakan, dapat datang dan pergi tanpa memiliki beban.

b. Third place tidak memiliki level

Pengguna third place tidak dilihat strata sosial maupun ekonominya. Dapat diakses oleh masyarakat umum tanpa memiliki kriteria yang diharuskan.

c. Conversation menjadi aktivitas utama Dapat memiliki fungsi interaktif, dapat membuat manusia akan berinteraksi lebih.

d. Accessibility and Accommodation Mudah untuk diakses bagi penggunanya.

e. Third Place memiliki The regulars Menjadi suatu tempat yang biasa dan umum.

f. A low profile building Bangunan sederhana, tidak mengintimidasi orang yang akan menggunakannya. Menyesuaikan dengan karakter kawasan.

g. Mood yang diberikan "playful"

Menghilangkan kesan kaku, diharapkan masyarkat di sebuah third place dapat merasa senang dan melakukan hal yang tidak membosankan. Memberikan kesan bahagia bagi penggunanya.

Di Jakarta, sebuah third place umunya adalah sebuah Mall dan café atau kedai kopi. Minimnya sebuah ruang publik bagi masyarakat untuk melakukan aktivitas yang biasa dilakukan di third place sehingga menjadikan sebuah Mall sebagai Third place. Sebuah Mall atau pusat berpelanjaan di Jakarta dijadikan third place karena masyarakat tidak memiliki sebuah tempat untuk melepas penat, pergi dari first place dan second place. Padahal Mall di Jakarta tidak memiliki karakteristik sehingga dapat dikatakan sebuah third place.

Cinema

Menurut Bazin (2005) dalam buku what is cinema?, Cinema dapat dibuat sebagai bentuk seni kebebasan dari seorang artis dari realita kehidupannya. Sebuah sinema merupakan relasi antara ekonomi dan revolusi teknis dan imajinasi dari orang yang membuatnya. Cinema merupakan sebuah fenomenal idealis. Sebuah sinema membutuhkan sedikitnya sebuah 
panggung yang transparan, fleksibel, dasar yang kuat untuk menerima sebuah gambar yang dapat di atur. Film yang dibuat sehingga dapat dinikmati di sebuah sinema, menurut bazin, orang yang menikmati sebuah film seharusnya dapat menghargai seni dan media pembuatannya secara keseluruhan.

Sebuah sinema membutuhkan sedikitnya sebuah panggung yang transparan, fleksibel, dasar yang kuat untuk menerima sebuah gambar yang dapat di atur. Film yang dibuat sehingga dapat dinikmati di sebuah sinema, menurut bazin, orang yang menikmati sebuah film seharusnya dapat menghargai seni dan media pembuatannya secara keseluruhan. Menurut Yudistira (2014) dalam Jurnal Bioskop Komunitas di Sleman D.I.Y Bioskop merupakan istilah untuk menyebut bangunan tempat pertunjukan sebuah film. Istilah bioskop lebih sering digunakan disbanding movie theater atau sinema.

Dalam artikel dari communitycinema.org, negara dengan perkembangan film yang sudah maju, salah satu contohnya di Amerika, bioskop mulai berkembang ke arah bioskop komunitas (community cinema) dengan kapasitas kecil, memiliki layar lebih dari satu dan memutar film dengan tema yang spesifik sesuai minat masyarakat sekitar. Tersebar di beberapa titik daerah sebuah kota dan dibangun karena permintaan dari masyarakat sendiri, dengan bantuan dari pemerintah. Dengan sistem ini, populasi menonton bioskop menjadi lebih terkendali karena disesuaikan dengan masyarakatnya. Kelebihan dari community cinema juga dapat digunakan menjadi sebuah community hall, atau fungsi pelayanan sosial dan bersedia memutar film independen buatan sineas lokal. Karena itu, film menjadi media penyebaran informasi, isu, dan penghubung kegiatan sosial masyarakat.

\section{Layar Tancap}

Menurut Erwanto (2014) dalam jurnalnya Bioskop Keliling Peranannya Dalam Memasyarakatkan Film Nasional Dari Masa Ke Masa, bioskop menjadi tempat bertemunya konsumen (penonton) dengan komoditas jasa yaitu film. Perkembangan bioskop komunitas dimulai dari layar keliling atau layar tancap. Awalnya layar tancap digunakan untuk propaganda oleh pemerintah jepang. Bioskop keliling dibuat karena minimnya gedung bioskop sehingga pemerintah jepang tidak dapat melakukan propaganda skala besar.

Pada tahun 1970 sampai dengan awal tahun 1980-an, layar tancap menjadi salah satu alternatif hiburan bagi masyarakat di pelosok daerah sampai dengan saat ini. Terlebih bagi daerah yang belum tersentuh bioskop besar. Bioskop keliling pada tahun 1970-an hanya berupa pancang bambu yang ditancapkan di tanah dengan layar membentang di tengahnya. Muncul istilah Misbar (gerimis bubar), karena jika turun hujan atau gerimis penonton langsung bubar.

Kegiatan dalam Layar Tancap yang dijelaskan oleh Dimas Jayasrana \& Ardi Yunanti dalam artikelnya Layar Tancep; Proyeksi Sebuah Pesta yaitu layar tancap menampilkan film tanpa jeda sehingga membuat penonton tidak melakukan aktivitas selain menonton. Terdapat anak kecil bermain, masyarakat muda saling menggoda, bahkan berpacaran serta terdapat pedagang kaki lima berjualan. Layar tancap menjadi fenomena ketika dapat melepaskan diri dan menciptakan aktivitas baru. Dengan tujuan utama mampu membuat pengunjung berinteraksi. Beberapa orang yang datang belum tentu ingin menonton film, tapi juga menonton penonton lain, atau hanya untuk menikmati suasana yang diciptakan oleh layar tancap itu sendiri.

Layar tancap identik dengan pertunjukan film yang berada di lapangan terbuka dengan penonton masyarakat kecil di kota. Namun layar tancap memiliki bentuk yang berbeda dengan konsep yang sama, yaitu menampilkan sebuah film tidak terikat pada suatu tempat. Bentuk lain dari layar tancap yaitu sebuah bioskop Drive-In dan pertunjukan special screening. 
Kontribusi positif telah diberikan oleh layar tancap terhadap perkembangan industri film nasional. Menjadi aspek dalam peredaran film Indonesia hingga ke pelosok desa. masyarakat dibuat terhibur juga dapat memahami bagaimana budaya Indonesia melalui sebuah film, menjadi cermin budaya.

\section{Bioskop di Jakarta}

Peminat di bioskop Jakarta saat ini masih tinggi, di luar dari maraknya menonton menggunakan perangkat lain ataupun melalui streaming. Berdasarkan data dari filmindonesia.oid.id mendata pengunjung bioskop di Jakarta, pada tahun 2019, pengunjung tahun 2017 sebanyak 42,7 juta penonton, meningkat menjadi 52 juta pada tahun 2018 dan 60 juta penonton pada tahun 2019. Dari data tersebut menunjukkan bahwa antusias masyarakat Jakarta untuk menonton film di bioskop semakin tinggi.

Bioskop di Jakarta saat ini di dominasi oleh bioskop komersil, dan beberapa bioskop independen. Bioskop sendiri biasanya berada di dalam pusat perbelanjaan, hanya beberapa yang memiliki gedung sendiri. Bioskop menjadi salah satu tujuan utama bagi pengunjung saat datang ke Mall. Menurut (Nuqul;2005) penonton yang pergi ke bioskop cenderung lebih individu, memilih tempat yang berjauhan dengan penonton lainnya kecuali datang secara kelompok yang sama. Selain itu penonton juga mengambil jarak sosial dengan orang yang belum dikenalnya sehingga interaksi antar penoton dalam kerumunan atau di tempat umum mempunyai dua pola. Jika belum saling mengenal akan menjauh dan jika saling mengenal akan berdekatan. Dalam hasil penelitiannya, lingkungan fisik maupun sosial dapat mempengaruhi perilaku individual.

\section{METODE}

Metode penelitian yang dilakukan adalah menggunakan metode deskriptif. Menjelaskan bagaimana keadaan sebuah third place di Jakarta saat ini, lalu bagaimana sebuah bioskop yang ada melalui pendekatan studi literatur dan studi kasus sebuah third place dan bioskop. Tahap pertama dimulai dari memahami teori tentang third place dan mengamati studi kasus sebuah third place di Jakarta. Tahap kedua yaitu meng-observasi keadaan bioskop saat ini dan mencari data pendukung. Selanjutnya hasil tersebut dibandingkan dengan kajian literatur tentang third place dan keadaan bioskop yang pernah ada di Jakarta untuk membuktikan bahwa sebuah cinema dapat menjadi sebuah third place.

\section{DISKUSI DAN HASIL}

\section{Open Cinema sebagai Ruang Ketiga}

Dengan keadaan di bioskop Jakarta saat ini, memberikan sebuah kesan bahwa bioskop adalah tempat yang privat, tidak dapat membuat penonton berinteraksi serta berkomunikasi secara bebas. Open cinema atau sinema terbuka mengambil konsep layar tancap atau misbar yang dari dulu sudah ada di Indonesia. Layar tancap yang tujuan utamanya adalah untuk memberikan hiburan di daerah yang sulit dijangkau ternyata dapat diterapkan di kota besar. Dalam pembahasan ini sebuah bioskop seharusnya dapat menjadi ruang ketiga sehingga dapat membuat penggunanya merasa nyaman, dengan memberikan aktivitas utama menonton film. Aspek yang perlu diperhatikan dalam pembuatan Open Cinema yaitu :

a. Interaksi sebagai tujuan utama

Jika dilihat keadaan bioskop saat ini, masyarakat yang datang hanya memiliki tujuan utama menonton film. Dengan suasana yang tertutup membuat bioskop lebih cenderung individu. Berbeda dengan layar tancap, masyarakat datang ke layar tancap tidak hanya untuk menonton sebuah film, tetapi juga untuk menikmati bagaimana suasana di layar tancap, melihat penonton lainnya yang datang, serta menjadi wadah untuk berinteraksi bagi 
penontonnya. Di kota Jakarta terdapat beberapa bioskop yang telah melakukan hal tersebut, yaitu sebuah bioskop independen. Sebuah bioskop dengan kapasitas dan skala yang lebih kecil dari bioskop pada umumnya. Penonton yang datang biasanya pecinta film, film antusias, serta masyarakat sekitar membuat pengunjung memiliki suatu kesamaan yaitu datang untuk menonton dan menikmati sebuah film.

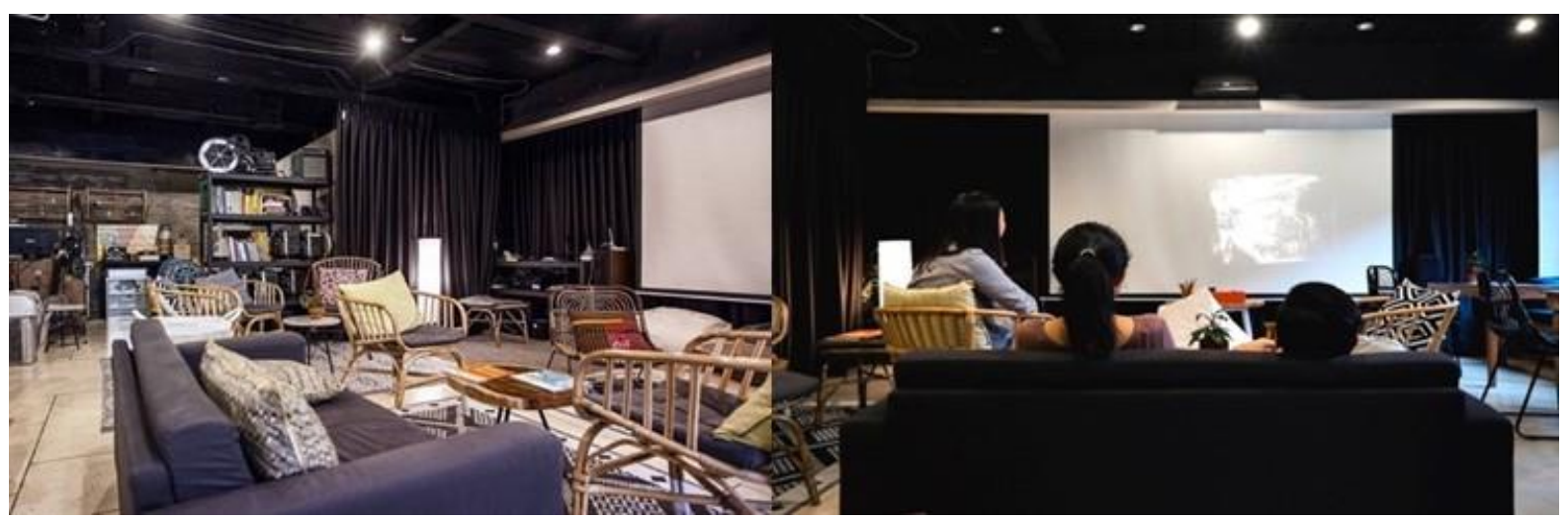

Gambar 1. Kinosaurus, bioskop mikro di Jakarta Sumber: Liveindo.com

Salah satu contoh sebuah bioskop independen adalah Kinosaurus di Kemang, Jakarta Selatan. Sebuah bioskop dengan konsep microcinema. Dengan memiliki jadwal pemutaran film di setiap hari Jumat, Sabtu, dan Minggu memberikan sebuah bentuk bioskop yang berbeda di Jakarta. Kinosaurus mendesain ruangannya menjadi lebih terbuka, lebih santai, tidak formal dan komersil seperti bioskop kebanyakan. Bioskop ini juga sering menjadi tempat untuk berkumpulnya penikmat film di Jakarta. Dengan begitu penonton dapat menjalin interaksi dikarenakan suasana yang tidak tertutup dan lebih santai.

Pemilihan film yang tepat juga dapat menjadi ruang interaksi bagi penontonnya. Dengan menyesuaikan film yang akan diputar, film dapat menjadi tools untuk saling berinteraksi. Film sebagai pemicu bagi penontonnya untuk mengungkapkan pendapat mereka, kritik maupun komentar baik sehingga terjalin komunikasi. Dengan dasar memiliki satu hal kesamaan yang dilakukan bersama yaitu menonton film bersama - sama. Interaksi menjadi tujuan agar Open Cinema dapat dikatakan sebuah third place dan sebagai pembanding dari bioskop - bioskop yang ada saat ini. Dengan adanya interaksi dan komunikasi antar pengunjung, bioskop dapat menjadi sarana hiburan serta menjadi ruang untuk interaksi masyarakat.

b. Desain Ruang Tidak formal

Menurut Nuqul (2005) dalam jurnalnya bahwa sebuah ruang menentukan tingkat interaksi dari penggunanya. Pengguna bioskop merasa tidak nyaman jika harus duduk berdekatan dengan orang yang tidak dikenal sehingga memilih kursi yang berjauhan jika bioskop tidak terlalu ramai. Jika belum saling mengenal akan menjauh dan jika saling mengenal akan berdekatan. Dalam hasil penelitiannya, lingkungan fisik maupun sosial dapat mempengaruhi perilaku individual. Dari sini dapat terlihat bahwa bioskop selama ini tidak mendukung penggunanya untuk saling berinteraksi. 


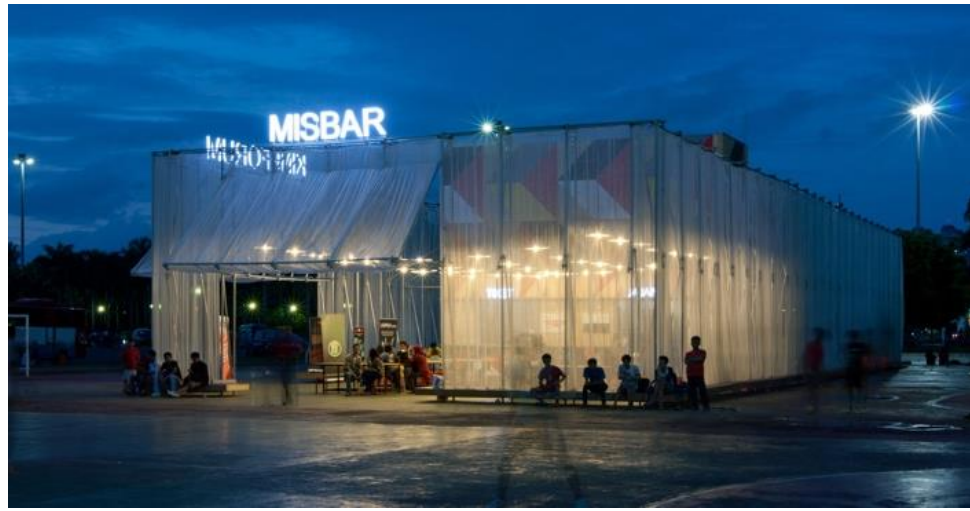

Gambar 2. Kineforum, Monas, Jakarta.

Sumber: Archdaily

Kineforum sempat membuat sebuah instalasi bioskop di Monas, Jakarta. Dalam instalasi ini kineforum berhasil membuat pengunjung dapat memberikan suasana menonton yang berbeda dari biasanya. Dengan menggunakan konsep Misbar (gerimis bubar) instalasi ini memberikan sebuah wadah yang dapat digunakan masyarakat kota untuk menonton film serta berinteraksi. Menyatukan berbagai macam lapisan masyarakat untuk menonton sebuah film bersama - sama. Dengan memberikan suasana menonton yang terbuka membuat antusias warga Jakarta untuk mencoba menonton film di instalasi Kineforum ini.

Dapat terlihat bahwa berusaha memberikan hiburan kepada masyarakat kota Jakarta seperti bioskop keliling atau layar tancap. Dengan penggunaan material yang mudah untuk di cabut pasang, membuat instalasi ini memberi kesan low profile, sesuai dengan karakteristik sebuah third place. Tidak mengintimidasi penggunanya sehingga semua orang merasa welcome berada di dalamnya. Open cinema dapat menjadi alternatif utama untuk membuat sebuah bioskop yang berbeda dari bioskop komersil yang ada. Dapat digunakan sebagai bioskop komunitas, maupun seluruh warga Jakarta yang ingin menonton sebuah film. Desain bioskop lain seperti sebuah cinema pod, mini cinema dengan kapasitas yang kurang dari 15 orang, cinema cafe juga dapat menjadi salah satu pilihan desain sebuah bioskop yang dapat menjadi third place di Jakarta.

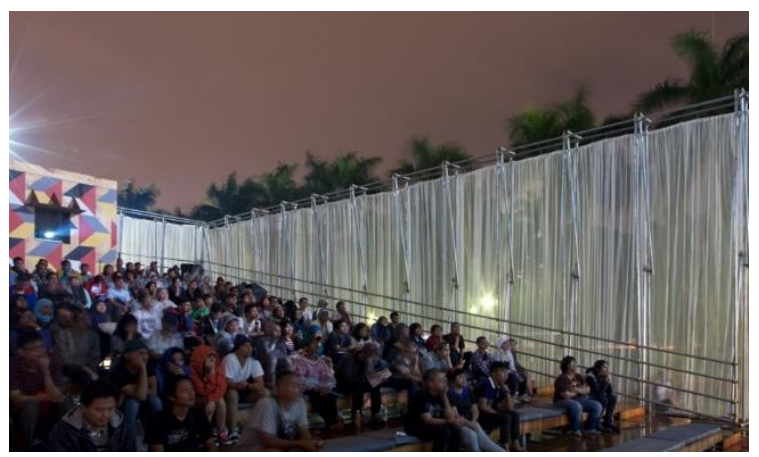

Gambar 3. Kineforum, Monas, Jakarta. Sumber: Archdaily

c. Memiliki fungsi pendukung

Memiliki fungsi pendukung menjadi aspek yang cukup penting agar sebuah sinema tetap dapat hidup. Fungsi pendukung sebuah sinema umumnya adalah area makan. Dalam proyek instalasi Kineforum (Gambar 2) terdapat sebuah area makan di foyer sebelum masuk menuju area pemutaran film begitu juga di Kinosaurus. 


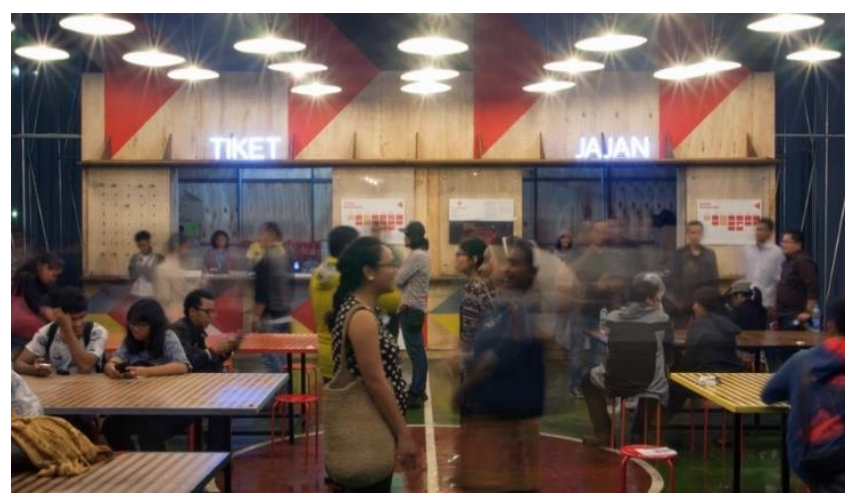

Gambar 4. Area makan instalasi Kineforum, Monas, Jakarta.

Sumber: Archdaily

Kinosaurus bergabung dengan Aksara, yaitu sebuah toko buku di kemang yang memiliki banyak program tambahan lainnya seperti tempat makan, coffee shop, toko ice cream, serta toko kamera analog. Fungsi tambahan biasanya menyesuaikan minat masyarakat saat ini, maupun kawasan sekitar lokasi. Dengan adanya fungsi tambahan dapat membuat Open Cinema tetap hidup jika tidak sedang ada pemutaran film.

d. Memiliki Bangunan sendiri, tidak bergabung dengan pusat perbelanjaan kota

Dari hasil observasi aktivitas tertinggi yang dilakukan masyarakat kota datang ke shopping mall adalah untuk menonton bioskop. Bioskop yang biasanya ada di Jakarta berupa sebuah bioskop komersil, jika ingin menonton bioskop harus datang ke sebuah pusat perbelanjaan. Muncul pertanyaan kenapa harus datang menuju sebuah shopping mall untuk menonton bioskop? Dengan Open Cinema memiliki bangunan sendiri, seluruh lapisan masyarakat dapat datang tanpa perlu merasa berada di tempat yang tidak sesuai. Jika berada di pusat perbelanjaan, tidak semua masyarakat mau untuk datang karena merasa tidak pantas. Dengan berada di bangunan tersendiri, terlebih di area terbuka, memberikan kesan suasana yang lebih santai.

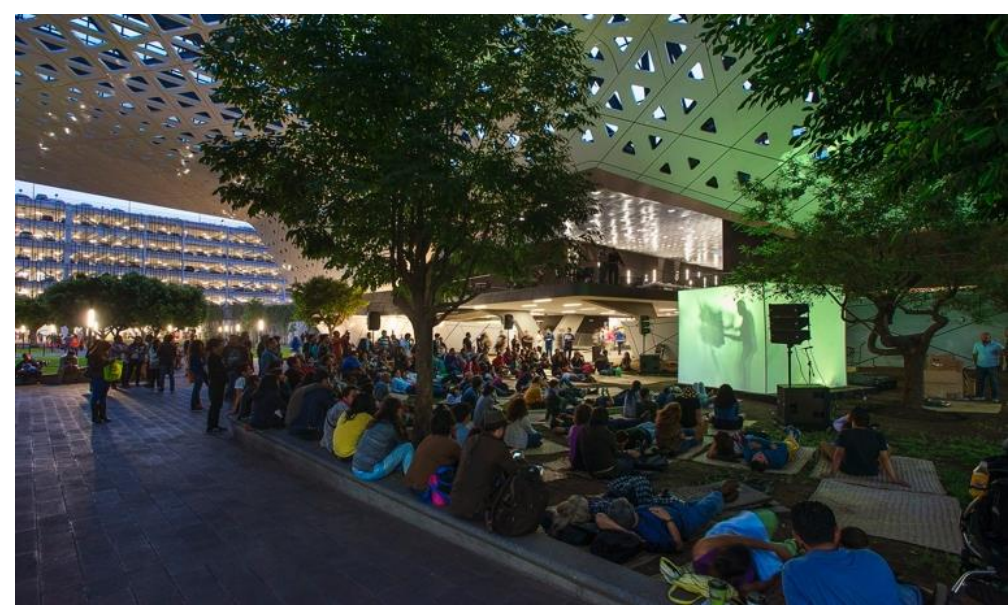

Gambar 5. Open Cinema sebagai ruang publik

Sumber: Archdaily

Berada di bangunan sendiri juga membuat sinema menjadi lebih mudah untuk diakses, sesuai dengan karakteristik dari third place menurut Ray Oldenburg.

Dari beberapa contoh bioksop di atas, memilki bangunan sendiri menjadi salah satu aspek yang cukup penting sehingga Open Cinema dapat disebut sebuah third place. Minimnya sebuah third place di Jakarta membuat masyarakat kota datang menuju pusat perbelanjaan 
dan menjadikannya sebuah third place. Jika sebuah bioskop menjadi sebuah third place, lebih baik terpisah dari pusat perbelanjaan, dengan menyesuaikan karakteristik sebuah third place.

\section{KESIMPULAN DAN SARAN}

Sebuah Open Cinema dapat menjadi sebuah third place. Open Cinema dapat menjadikan penonton dapat saling berinteraksi satu sama lain, serta dapat memberikan suasana menonton film yang berbeda dari bioskop yang ada di Jakarta saat ini. Open cinema juga dapat menjadi wadah untuk masyarakat untuk mendapatkan hiburan menonton film bagi semua kalangan masyarakat. Open Cinema dapat Dengan mengikuti konsep bioskop jaman dulu yaitu layar tancap yang bertujuan memberikan masyarakat ruang untuk lari dari rutinitas kota dan rehat dari kebiasaan yang rutin dilakukan selama ini.

Open Cinema memiliki aspek yang dapat membuatnya menjadi sebuah third place yaitu menjadikan interaksi sebagai tujuan utamanya. dengan film sebagai tools untuk saling berinteraksi. Film sebagai pemicu bagi penontonnya untuk mengungkapkan pendapat mereka, kritik maupun komentar baik sehingga terjalin komunikasi. Dengan dasar memiliki satu hal kesamaan yang dilakukan bersama yaitu menonton film bersama - sama.

Aspek yang kedua adalah area menonton film dibuat tidak formal. Dengan desain sebuah Open Cinema yang tidak kaku seperti bioskop komersil di Jakarta, sebuah Open Cinema dapat membuat penonton menjadi lebih santai. Tidak menjadi fokus kepada masing - masing individu yang datang, menjadi lebih sadar dengan sekitar. Memberikan suasana menonton film yang berbeda dari bioskop yang ada saat ini.

Terdapat beberapa kemungkinan untuk sebuah desain bioskop tidak formal yaitu Open Cinema, Cinema Pod, Cinema cafe, dan Mini Cinema. Open Cinema dapat menjadi alternatif utama untuk membuat sebuah bioskop yang berbeda dari bioskop komersil yang ada. Dapat digunakan sebagai bioskop komunitas, maupun seluruh warga Jakarta yang ingin menonton sebuah film. Cinema pod dapat menjadi salah satu alternatif untuk memberikan ruang bagi penonton untuk menonton film, dapat menjadi salah satu pilihan untuk hiburan jika lelah dengan rutinitas kota. Selanjutnya adalah cinema cafe, fungsi cinema dapat digabungkan dengan fungsi lain yaitu sebuah cafe sehingga lebih terbuka dan dapat berinteraksi secara lebih leluasa. Terakhir adalah sebuah Mini Cinema. Sebuah Mini Cinema dapat menjadi salah satu pilihan untuk menonton film dengan skala kecil, dengan jumlah kapasitas yang kecil, menjadi lebih dekat dan santai bagi penonton film.

Memiliki fungsi pendukung juga menjadi aspek yang perlu diperhatikan. Dengan adanya fungsi pendukung dari sebuah bioskop, dapat membuat bioskop tetap hidup jika tidak sedang ada pemutaran film. Biasanya fasilitas pendukung sebuah cinema adalah Menjadi bagian pendukung dari yang dapat melengkapi sebuah Open Cinema. Aspek yang terakhir adalah sebuah Open Cinema memiliki bangunan tersendiri, tidak bergabung dengan sebuah pusat perbelanjaan. Dengan memiliki bangunan sendiri, pengunjung tidak akan segan seperti datang ke sebuah Mall. Lebih merangkul semua lapisan masyarakat yang datang untuk melihat sebuah film secara bersama- sama, semua orang memiliki derajat yang sama di dalamnya dan dengan tujuan yang sama yaitu menonton sebuah film.

\section{REFERENSI}

Azasya, S. (2020). [INFOGRAFIS] Minat Penonton Terhadap Film Indonesia, Banyak Gak Sih?, $\begin{array}{llll}\text { diunduh } 13 & \text { February 2020, }\end{array}$ https://www.idntimes.com/hype/entertainment/stella/infografis-minat-penonton terhadap-film-indonesia/full

Bazin André, Gray, H., Truffaut François, \& Andrew, D. (2005). What is cinema?. Berkeley: University of California Press. 
Cineteca Nacional Siglo XXI / Rojkind Arquitectos. (2014). Retrieved February 19, 2020, from https://www.archdaily.com/478325/cineteca-nacional-s-xxi-rojkindarquitectos/?ad_source=myarchdaily\&ad_medium=bookmarkshow\&ad_content=current-user

Erwantoro, H. (2014) Bioskop Keliling Peranannya Dalam Memasyarakatkan Film Nasional Dari Masa Ke Masa. Patanjala : Jurnal Penelitian Sejarah Dan Budaya, 6(2): 285 doi:10.30959/patanjala.v6i2.200.

Jayasrana, D., Yunanto, A. "Layar Tancep; Proyeksi Sebuah Pesta", Film Alternatif, www.filmalternatif.org/?m=article.detail

Jusuf, W., \& Kurniawan, F. (2018). Bioskop Alternatif di Mata Penonton. Diunduh 13 Maret 2020, https://tirto.id/bioskop-alternatif-di-mata-penonton-cGW9

Luco, A. (2019). Litt Bar / LCAC Arquitetura. Retrieved December 4, 2019, from https://www.archdaily.com/929512/litt-bar-Icac-

arquitetura/?ad_source=myarchdaily\&ad_medium=bookmarkshow\&ad_content=current-user

Matthews, T., \& Dolley, J. (2019). Many people feel lonely in the city, but perhaps 'third places' can help with that. Retrieved November 26, 2012, from https://theconversation.com/many-people-feel-lonely-in-the-city-but-perhaps-thirdplaces-can-help-with-that-92847

McLaren, D., \& Agyeman, J. (2017). Sharing cities a case for truly smart and sustainable cities. Cambridge, MA: MIT Press.

Nuqul, F. L. (2005). Pengaruh Lingkungan Terhadap Perilaku Manusia: Studi Terhadap Perilaku Penonton Bioskop. Psikoislamika: Jurnal Psikologi Dan Psikologi Islam, 2(2). doi:10.18860/psi.v0i0.343

Oldenburg, R. (1997).The Great, Good Place. Cambridge: Da Capro Press.

Redaksi. (2020). 67 Persen Anak Muda Indonesia Menonton Film Nasional dan Hanya 55 Persen Menonton Film Asing. Diunduh 16 Januari 2020, https://saifulmujani.com/67persen-anak-muda-indonesia-menonton-film-nasional-dan-hanya-55-persen-menontonfilm-asing/

Yudistira, M. D. (2014). Bioskop Komunitas Di Sleman D.I. Yogyakarta. 